\title{
Fossil Human Bones, possibly of Pleistocene Age, found in Egypt.
}

$A^{T}$ a meeting of the Royal Anthropological Institute, held on July I7, Prof. C. G. Seligman, president, in the chair, Dr. D. E. Derry described the fossilised human bones recently discovered in Egypt. which, on the ground of their condition, he is inclined to regard as of Pleistocene age. The discovery is one of very considerable importance, as this is the first occasion on which fossilised human bones have been obtained from Egypt. Early in January of the present year Mr. Guy Brunton, while excavating for the British School of Archæology in Upper Egypt, found at Gau-el-Kebir, on the east bank of the Nile, about thirty miles south of Assiut, a remarkable collection of bones, mostly animal, but with pieces of human bones mixed with them in the heap. Some of the bones, including the human fragments, were heavily mineralised, while others were only partially so, and some not at all. The whole collec. tion was contained in an Early Dynastic grave, and had obviously been placed there for some purpose. Among the bones were carved bone and ivory objects of the XIXth Dynasty. The presence of the latter is explained on the assumption that this was the site of a workshop for the manufacture of articles in bone and ivory, and that the great heap dumped into the pit of an early grave represented the workman's material. The presence of freshwater oyster shells attached to some of the bones proves that they came from the river, or, what is more likely, from a swamp fed by the river, which in all probability was much nearer the site of the discovery than it is now The bones exhibit evidence of having been exposed for a long time to the mineralising ifflluence, as they are very heavy, black, and highly polished, probably from the friction of waterborne sand.

The first evidence of human fossil bones in the heap was found by Mr. Brunton. This consisted of the right half of a frontal bone. Afterwards the whole heap, probably about two tons of bones, was gone through and several other fragments both of skulls and limb bones were recovered. Pieces of three skulls were found, as well as part of a mandible. Fragments of hip bones, upper and lower limb bones, and an axis vertebra were also obtained. Two skulls are represented only by the frontal bone of each. These are remarkable for their small size and shallowness, with consequent small brain capacity. The third skull consists of the whole right parietal bone with a large part of the left parietal, welded into one piece. As it stands this appears to have been a well-shaped head with a maximum cranial breadth of $143 \mathrm{~mm}$. This fragment is, however, much more heavily mineralised than the two frontal bones, which would appear to have belonged to a more primitive face. Some very unusual anatomical features are exhibited by the mandibular fragment and also by the piece of a right ilium.

The position in which the bones were found precludes the possibility of assigning them to any geological period; but an examination of the animal remains by Prof. Watson has revealed the presence of at least two extinct animals, a crocodile and a buffalo, both of Pleistocene date, while the mineralisation of the human fragments is as extensive as that of any of the animal remains.

In the discussion which followed the reading of the paper, Sir W. M. Flinders Petrie pointed out that in regard to the dating of the bones it must be remembered that owing to the constant and consistent deposit of mud by the Nile, amounting to about $3 \frac{1}{2} \mathrm{ft}$. in a thousand years, the bed of the river was rising continually: Any object deposited while the Nile was thus rising would be lost irretrievably beneath the mud. These bones must therefore have been deposited while the Nile was falling from six hundred feet above to one hundred feet below its present level. The date of deposition must therefore be at least I5,000 years ago, plus the time occupied by the fall of the river to the level of the swamp which had been postulated as the place of deposit.

Sir Arthur Keith said the discovery was extraordinarily interesting and puzzling. These fossilised bones, the first to be found in Egypt, presented no outstanding features marking them off from modern man, and no diagnosis of race was possible, but this did not preclude their high antiquity, and they might well be Pleistocene. Fragments of hippopotamus bone from the Nile mud, now at South Kensington, exhibited staining and a high polish exactly similar to that of some of Dr. Derry's specimens. Sir Arthur laid stress on the importance of the fringes of the great desert belt as the possible site of the evolution of our race; Dr. Derry's discovery, though we could not place it exactly, was of the first importance. Probably men of our type existed in Egypt more than 18,ooo years ago, and populated Europe, possibly more than once. Prof. Seligman said the cubic capacity of ro4o c.c. of the small skull suggested a comparison with the smaller skulls from the Thebaid described by Dr. Randall-Maclver, and, in conjunction with the steatopygous predynastic figures discovered by Sir W. M. Flinders Petrie, pointed to the necessity of a further comparison with Bushmen skulls.

\section{Recent Fisheries Investigations.}

SOME very interesting reports, in continuation of Series II. (Sea Fishery Investigations), have recently been published by the Ministry of Agriculture and Fisheries. No 6 of vol. 4 is written by Mr. J. O. Borley, and describes the samples of bottom deposits collected in the southern North Sea by the vessels of the Marine Biological Association. The report is illustrated by charts and many very beautiful photographs. The deposits are graded in various ways, partly by mechanical sieving and partly by a method of levigation, and the results show a correspondence between the average sizes of the particles and the transporting power of the current systems. In general the particles are coarsest where the tidal streams are most rapid, and vice versa. It is not improbable that there is attrition of particles on the sea bottom, but this cannot be very great. At 20 fathoms (that is, not far from the average depth of the North Sea) the currents are competent to grade bottom materials: at this depth wave action on the surface has a notable effect at the bottom.

No. I of vol. 5 is a summary of very extensive market statistics, collected in regard to the cod, during the years I9I3-I4. No. 2 of vol. 5 is highly important. It is written by Mr. H. J. BuchananWollaston, and deals with the spawning of the plaice in the southern North Sea (the Flemish Bight) during the years $193^{-1} 4$. The method is an extension of the Hensen quantitative plankton one, but novel and beautifully manageable mathematical methods of dealing with the results have been developed: some of these are highly ingenious, and have, perhaps,

No. 2807 , VOI.. I I 2 ] 
application to problems other than those for which they have been devised. The results are interesting almost to the degree of being "sensational." 'In January of I9I3-I4 the rate of production of plaice eggs over the whole area sampled was 180,000 millions per 3 days, and in February the rate dropped to I57,00o millions per 3 days. That works out at about two million million eggs per month and about five million million per year. To produce these eggs some twenty millions of female plaice at least must have been required. The rate of mortality is very high, and only about Io to 30 per cent. of the eggs hatch out. The production was far higher in I9I4 than in IgII.

No. 3 of vol. 5, written by Mr. J. O. Borley and his collaborators, deals with the plaice fisheries during the war years, and discusses the results of the special investigations made in various parts of the British sea-fishery area. The report and recommendations of the plaice committee of the International Fishery Council are appended.

No. 4 of vol. 5 breaks entirely new ground so far as the British sea fisheries are concerned. It is an account of the various kinds of gear now used in sea fishing in England and Wales, and has been written by Mr. F. M. Davis. The descriptions are clear; the drawings are very well done, and the Report represents a vast amount of very careful local investigation.

\section{J.J.}

\section{The Floor of the Valley of Ten Thousand Smokes.}

THE amazing display of fumarole action over an area of some fifty square miles, which arose in association with the volcanic outbreak of Mt. Katmai in Alaska in I9I2, was described and illustrated by its discoverer, R. F. Griggs, in Niture, vol. IOI, p. 497 (I9I8). In I920 (vol. Io4, p. 595), J. W. Shipley, of Winnipeg, chemist to the first Katmai expedition, gave an illustrated account of the "great mud-flow" through which the vapours fume, and he attributed the material to an eruption of Mt. Novarupta, preceding that of Katmai. He concluded that the spreading of the volcanic dust and scoriæ down the valley towards the Bering Sea was assisted by rains, and that heat from below had hardened the surface and produced the cracks that traverse it.

The National Geographic Society, which organised the expedition led by Dr. Griggs, has now begun the publication of a series of scientific memoirs on special features of the district, following on the general description that was noticed in NATURE, vol. III, p. 269 (I923). No. I of the "Katmai Series" of contributed papers is on "The Origin and Mode of Emplacement of the great Tuff Deposit of the Valley of Ten Thousand Smokes," by the well-known petrologist Clarence N. Fenner, of the Geophysical Laboratory of the Carnegie Institution of Washington.

The author finds, from a thorough study of the valley-floor, that the tuff was erupted from a large number of vents that opened along fissures mainly occurring in the lowland, and that these fissures determine the present lines of fumaroles. The fragmental material flowed while hot enough to char all vegetation in its path; no doubt it was still liberating gases, and the phenomena of Mount Pelée of Martinique were repeated. Katmai exploded somewhat later, since its ashes rest upon the volcanic detritus connected with the fumaroles.

Most of this detritus consists of highly siliceous glass, which has caught up basic matter from older igneous rocks; the mixed blocks possibly come from the moraines around Novarupta, the cone of which is formed of a soda-rhyolite that has penetrated and mingled with a dark medium andesite (p. 56 of memoir). But the author regards it as more likely that similar rock underlies the valley generally. Jurassic sandstones and shales have been blown to fragments by the explosions in the valley-floor; but the source of the andesitic admixture has not been traced here or at Novarupta.

Dr. Fenner's conclusion is that a sill of igneous rock penetrated the sedimentary series beneath the valley, burst into explosive activity along the cracks that opened, and deluged the country with fragmental matter that continued to give off gases and to spread as a quasi-liquid towards the coast. The numerous beautiful photographs accompanying his contribution, including several of Novarupta, complete its value as a petrological study carried out mainly in the field. We may now regard the Valley of Ten Thousand Smokes as one of the finest examples of the uprise and emanation of magmatic waters, and as a further reminder that igneous rocks as they reach us in hard specimens are something very different, both chemically and physically, from their representatives in the cauldrons of the crust.

Grenville A. J. Cole.

\section{Cultivation of Metal Crystals by Separation from the Gaseous State.}

F KOREF describes experiments on the deposi- tion of crystalline tungsten on a wire consisting of a single tungsten crystal, which is heated electrically in à mixture of hydrogen and tungsten hexachloride vapour in an electric oven. ${ }^{1}$ When the oven is fairly cool (about $I I O^{\circ} \mathrm{C}$.) and the pressure is kept down to $12 \mathrm{~mm}$. of mercury, the wire being raised to $1000^{\circ} \mathrm{C}$., the metal deposits in crystalline form, growing from the unit crystal, so that the dividing line between the two is scarcely visible in a magnified section, which, when etched, shows the characteristic structure of a tungsten crystal. The external form shows more or less distinct crystalline surfaces and edges, though the surfaces are not perfectly plane, being sometimes concave cylindrical, while the edges are not always sharp. It is concluded, however, that the whole mass forms one crystal, which has grown from the original crystal wire. The number of bounding surfaces seems to depend on the direction of the crystal axis in the original wire, the prism being four-, six-, or eight-sided. The diameter can be increased from 0.05 to $0.15 \mathrm{~mm}$., the temperature being kept constant during the deposition by regulating the heating current.

Although the original wire is flexible the crystal grown from it is brittle; but it becomes flexible after being heated for a few minutes to $2500^{\circ} \mathrm{C}$. ; no difference in the structure can be observed after this annealing, eithier microscopically or by X-ray examination. Burger has made a similar observation on tin crystals, obtained from molten tin. Apparently the atoms do not alter their positions during the heat treatment; but in some way, possibly by rotations about their centres, come into new relative relations to one another, and link together more perfectly to form a stronger and more flexible whole.

If the attempt is made to cultivate the crystal beyond the dimensions given above, the surfaces become deformed by the growth on them of numerous small pyramids, the molecules (atoms) no longer

NO. 2807 , VOL. I I 2 ] 